tended. Dr. Otis of New York has recently demonstrated the truth of Sir Everard Home's observation: "That the urethra is everywhere much larger than had been supposed, exceeding the size of the largest bougie in use in a very great degree."* And what is true of the healthy urethra will be found to apply, though in a less degree, to the strictured one.

The adaptations in Holt's dilator, specially fitting it for this purpose, may be briefly stated. In the first place, there is attached to it a pilot bougie, which, in cases of tight or tortuous strictures, will be found invaluable. Though the pilot bougie may not be necessary for all case where stretching is to be employed, yet, as this treatment is intended for some of the worst forms of the affection, it is as well to be prepared for every contingency. If the pilot bougie be not required, a round-top screw takes its place. Then I have increased the number of dilating rods to eight, so that the process of stretching may be gradual; and, in order that there may be no jerking as the several rods are introduced, a spiral spring controls the separation of the two portions of the instrument, instead of a screw.

The size of the dilator, before a rod is introduced, is No. 3, English gauge; the largest dilating rod brings it up to rather over No. 12-so that, between these two extremes, we have seven gradations in size. If the stricture is so tight as not to be capable of receiving the dilator, dilatation by means of filiform bougies must first be employed until the required size is obtained. Other instruments, divulsors and screw. dilators, as they are termed, have been invented for a similar purpose ; but all I have seen are open to two objections : I. They either tear or pinch with their sides the mucous lining of the urethra; 2. They are too large for use, except for strictures of the largest calibre. One of the best divulsors I know of is that adapted by Dr. Samuel Gross of Philadelphia. It is provided with an index at the handle, which shows precisely the extent to which divulsion has been carried.

A word or two in reference to the use of the instrument I employ for stretching. The patient being placed under ether, in the recumbent position, the dilator, with or without the pilot bougie, is passed fairly into the bladder, and then the rods are slowly and gradually introduced until a full size is obtained. The process generally occupies from ten to thirty minutes, according to the resistance, care being taken not to tear, and so eause hæmorrhage. I then withdraw the dilator, and pass a catheter, for the purpose of removing any urine that may be there. I usually give a dose of Fleming's tincture of aconite immediately after the stretching has been practised, and require the patient to remain in the house for twenty-four hours. A full-sized bougie is then passed every third or fourth day, until the patient has learnt how to conduct this operation himself, when he must be enjoined to continue this practice.

It will be seen that this proceeding differs essentially from what is so well known as Holt's operation. In the one, the object to be attained is stretching; whilst, in the latter, it is rupture. It is the only plan of treatment by which the strictured urethra is at once brought up to a full capacity, without break of tissue.

In conclusion, I would remark that I am not recommending this as 2 panacea, or as prejudicing other proceedings to which reference has been made; but as a safe and an efficient expedient for meeting imme. diate difficulties, and simplifying future treatment. If, in all cases of retention occurring with tight stricture, the use of this, or a similar instrument, followed the passing of the catheter, both patient and practitioner would be none the worse for the knowledge, that, whatever spasm might temporarily do, at all events there was a way to the bladder which had been made withnut any structural detriment, capable of admitting a No. 12 bougie. The dilator, as adapted for this purpose, was shown by Messrs. Krohne and Sesemann, in the International Medical and Sanitary Exhibition.

* On the Treatment of Strictures. Third Edition, p. 24.

ROYAL INSTITUTION. - The forthcoming arrangements for the delivery of Lectures at the Royal Institution will include the usual Christmas course of six lectures, to be given this year by Professor R. S. Ball, the Astronomer Royal of Ireland, on the sun, moon, and planets (with illustrations by the electric light, etc.); eleven lectures by the new Fullerian Professor of Physiology; four lectures by Professor $H$. N. Moseley on corals ; four lectures by Dr. P. S. Sclater on the geographical distribution of animals; and three lectures by Professor Tyndall. The Friday evening meetings will begin on January 2oth, at 8 P.M. Dr. W. Huggins will give a discourse on comets. Succeeding discourses will probably be given by Mr. R. S. Poole, Professors Odling, Frankland, J. G. McKendrick, and W. E. Ayrton, Captain Abney, Mr. A. Tylor, Mr. T. W. Swan, Mr. W. Spottiswoode, and other gentlemen.

\section{ON A CASE OF CONSERVATIVE SURGERY.} By THOMAS ANNANDALE, F.R.S.E.,

Regius Professor of Clinical Surgery in the University of Edinburgh.

IN the Exinburgh Medical fournal for June 1865, I published an account of the dissection of an arm, and illustrated the appearances met with by means of a woodcut, reproduced in Fig. I. This arm was

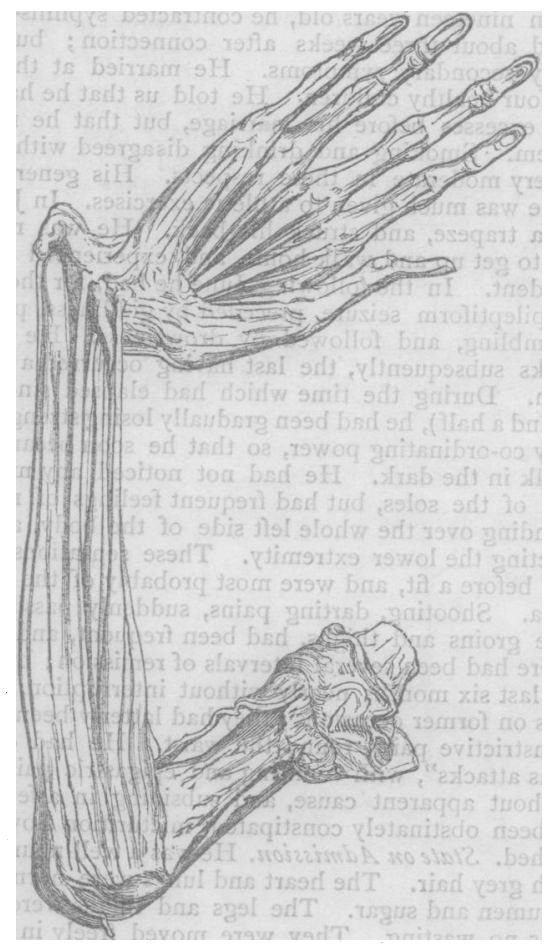

Fig. I.

sent to me by the late Dr. Fiddes of Jamaica, with the history that several years before the patient's death he had excised the entire radius for disease. A good recovery resulted, and the man was able to fol. low his employment, as a ship's pilot, until shortly before his death. The dissection of the arm showed that there had been no reproduction of the excised bone, but the hand had become turned round towards the radial side of the forearm, and its carpus articulated with this aspect of the ulna, which bone had become hollowed out at the point of articulation. The knowledge obtained by the history of the patient and by the dissection of his arm enabled me to practise the following conservative operation with success.

J. R., aged 34, mechanic, was admitted into the Edinburgh Royal Infirmary on the I 5 th November 1880. In May 1878, the patient fell and injured his left wrist. The accident was followed by swelling and pain, which symptoms were treated by various medical men by the application of splints and soothing lotions. After a few months of this treatment, he returned to his work; but the wrist remained swollen and stiff. One year after the accident, he noticed that the swelling was decidedly increasing in size; and, on seeking the advice of a surgeon, he was told that there was a tumour growing from the bone, and that a fracture of the bone had taken place in An operation was performed, and the tumour, together with some fragments of bone, was removed, and he returned to his work in about a month. Two weeks after this, the swelling again appeared; and, on applying again to his surgeon, he advised him to have the hand and wrist amputated. Before submitting to this proceeding, the patient came to Edinburgh to seek my opinion on his case; and, at first sight, I was inclined to agree with his own surgeon, and also recommend amputation. The condition of the disease, when seen by me, was as follows. There was a soft, lobulated tumour, of the size of a large cricket-ball, springing from the tissues on the dorsal and radial aspects of the wrist. The tumour involved the skin, and was firmly connected with the lower end of the radius for an extent of nearly 
three inches, this portion of bone being partially destroyed and somewhat expanded. The lower end of the ulna was not implicated, and the extensor tendons were stretched orer the tumour. As far as could be ascertained, the growth was confined to the parts mentioned, and no glandular enlargement could be detected. The movements of the wrist were very slight, but the fingers had fair movement.

In considering the treatment of the case, I had to take into account the fact that, in order to remove the disease without amputation, nearly four inches of the lower end of the radius, together with the tumour and skin over it, would require to be taken away; and also that, if a corresponding portion of the lower end of the ulna were excised so as to allow the carpus to become connected with the divided end of the radius, the result would be an useless and flail-like hand. Remembering the condition of the parts in Dr. Fiddes' case, I decided to try to save the hand by removing the lower end of the radius and the tumour, and then bringing the hand round, so that the carpus might make an articulation with the radial portion of the lower end of the ulna.

On November rgth, I performed this operation, taking special care to avoid as much as possible any injury of the extensor and other tendons. As all the affected skin required to be removed, a sore of the size of two half crowns remained after the operation. The operation was per. formed with careful Listerian precautions, and the hand and arm were placed upon an angular splint, specially made for the purpose of keeping the hand in the position referred to.

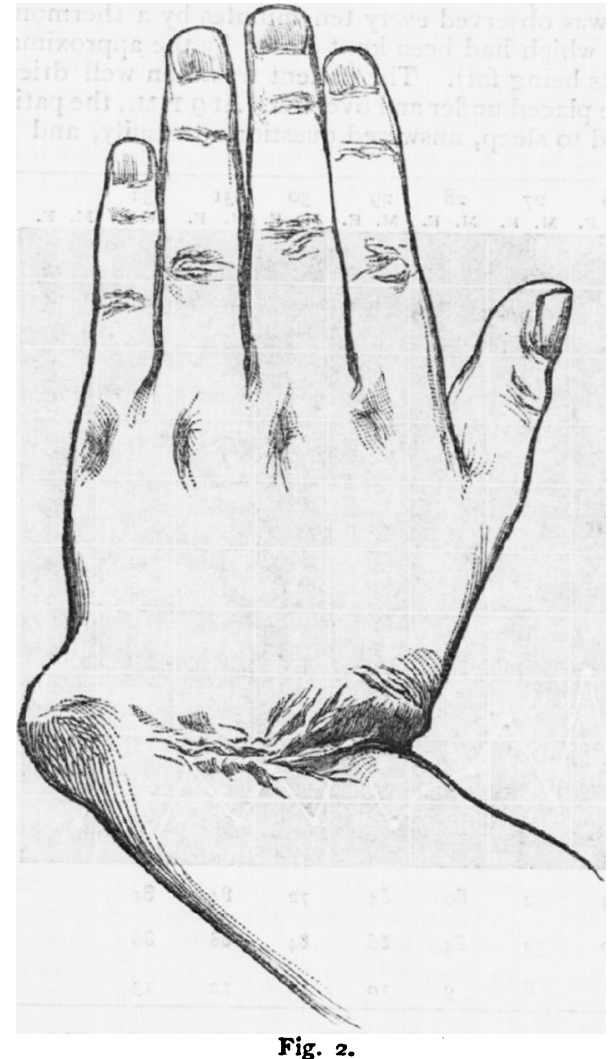

On January 7 th, $188 \mathrm{I}$, the antiseptic dressing was removed, as the wound was small and superficial. Careful movements of the wrist and fingers were commenced about a month after the operation, and these were regularly continued.

On February 14th, the patient left the hospital with the wound quite healed. His fingers had considerable mobility, and he had also some power of flexion and extension at the wrist.

In July of this year, the patient returned to show the result. The hand, fingers, and wrist had improved much in strength and mobility.

A cast of the hand and wrist was taken at this visit, and the illustra. tion shown in Fig. 2 is a careful copy of it.

Presentation to Dr. P. O'Connor.-A meeting was held at the West Derby Union Workhouse, on November $24 \mathrm{th}$, for the purpose of presenting a handsome writing-desk to Dr. P. O'Connor, by the officers of the workhouse. A second presentation was made, through the master, by the inmates of the union hospitals, with which Dr. O'Connor has been connected as resident medical officer for nearly three years.

\section{A NEW AND RELIABLE OPERATION FOR THE CURE OF WEBBED FINGERS.}

\author{
BY ARTHUR T. NORTON, F.R.C.S., \\ Surgeon and Lecturer on Surgery at St. Mary's Hospital.
}

C. K. was sent to me by Mr. Moore of Chiswick. The boy, one of four children, was about four years of age, and had the three inner fingers of the left hand webbed together. No relative had suffered from the same deformity. The operation which I performed can be best explained, and, indeed, can only be understood, by referring to the diagram.

A tongue of integument was cut from between the knuckles, and another, corresponding in shape, and position, and size, on the palmar surface. These tongues were then raised by dissection, and the webs cut through. The knife was then carried back so as to sever all the tissues as far back as the bases of the tongues, and a little superabundant tissue was removed. Next, the apices of the tongues were sewn together, and lint, dipped in cold water, applied. The flaps or tongues united by the first intention between the little and ring fingers, but one of the pair between the ring and middle firgers sloughed at its apex from its suture. The cause of the sloughing was incomplete section of the tissue between the fingers up to the base of the tongues, the result of which was too great tension, and consequently giving way, at the suture. However, even in this case, the tongues separated only a very short distance, and the interspace rapidly healed, so that there was no redevelopment of the web.

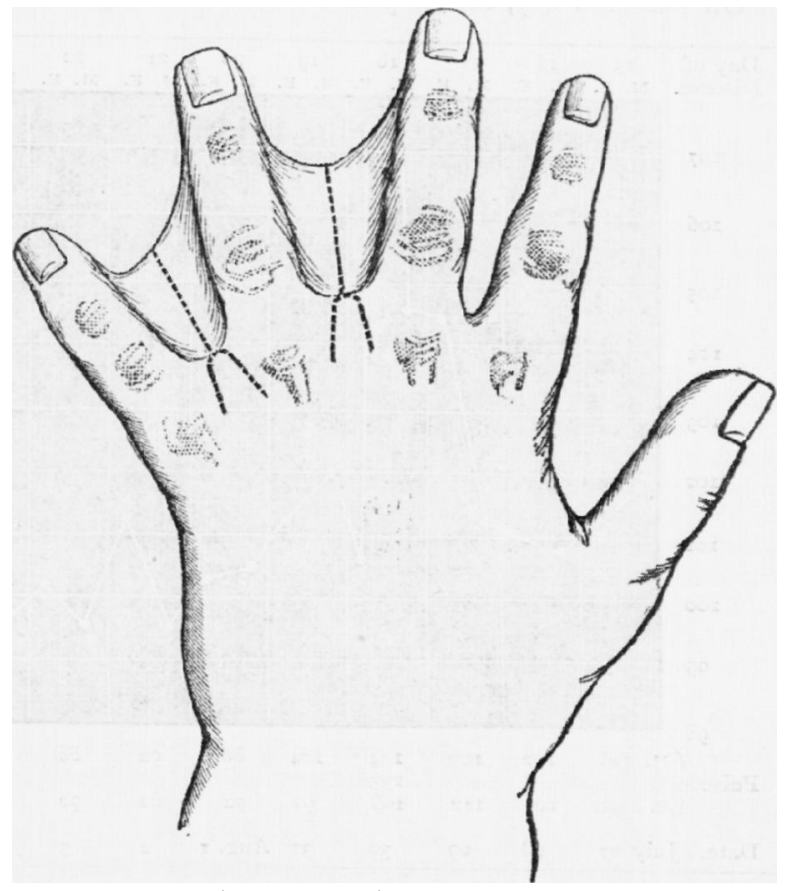

A drawing of the hand was taken after the operation, by which it will be seen that, in the case of the middle and third finger, a little more tissue might have been removed with advantage after the raising of the tongues, in order to bring the line of the natural web into proper position. The healing of the fingers progressed rapidly in the middle finger and on the outer side of the ring finger. Between the ring and little fingers the healing was not so rapid, because the web between these fingers was thick and narrow, so that, after its section, a larger surface was denuded.

The points to be considered in performing the operation are these. $I$. The tongues should be cut thick, so that their vascular supply may be complete, and the chance of their sloughing reduced to a minimum. 2. They should be cut rather narrow, with judgment; otherwise, they are compressed laterally and bulge upwards at the margins, instead of lying in adaptation to adjacent tissues. Such compression, of course, interferes with their circulation. 3. The tissue between the knuckles is to be cut back, or, if necessary, cut away, so that the apices of the tongues shall lie well in contact with each other without tension. 4. The tongues must be of sufficient length, so that there shail be no tension 